\title{
Evaluation of health-related quality of life in patients with chronic obstructive pulmonary disease
}

\author{
Taghreed S. Farag a, Eman S.M. Sobh ${ }^{a}$, Sawsan B. Elsawy ${ }^{a}$, \\ Bardees M. Fahmy
}

\begin{abstract}
Introduction The quality of life plays an important role in chronic disease management, including chronic obstructive pulmonary disease (COPD).
\end{abstract}

Objective To assess the quality of life in COPD patients and its relationship to disease severity.

\begin{abstract}
Patients and methods Two hundred Egyptian COPD patients were included in the study. We collected demographic data, comorbidities, dyspnea score, and other symptoms. Spirometry, 6-min walk tests were also conducted. Health-related quality of life (HRQoL) assessment was done with the Arabic version of St George's Respiratory Questionnaire.
\end{abstract}

Results There was male predominance (72\%); in most of the cases $(79 \%)$, there were more than 50 years old. COPD patients who had significantly reduced HRQoL. Age, frequency of exacerbations per year, comorbidity, particularly hypertension and ischemic heart disease, modified Medical Council Research Dyspnea scale dyspnea scale, BODE index, GOLD spirometric staging, and New GOLD stage showed significant positive correlation with St George's

\section{Introduction}

Health-related quality of life (HRQoL) is composed of various domains that involves physical, mental, and social wellbeing; which greatly varies for each patient [1]. Impaired quality of life ( $\mathrm{QoL})$ is closely related to shortness of breath, impaired physical activities, and mental problems including; depression, anxiety, and psychological disorders [2,3]. Chronic obstructive pulmonary disease (COPD) is linked with impaired daily activities (DAs), and reduced HRQoL [4]. Numerous studies [5-7] identified that lower education level, more breathlessness, fatigue, lower BMI, and depressive symptoms adversely affect the HRQoL. QoL in COPD can be measured in nearly 30 min through St George's Respiratory Questionnaire (SGRQ) [8]. The Egyptian-Arabic version of SGRQ is validated, reliable, and easy to understand [9]. The SGRQ is a self-administered questionnaire that examines three domains through 50 items with 76 weighted responses. The questionnaire has two parts; part I produce the 'symptoms score', which examines respiratory manifestations, frequency, and severity; and part 2 'the activity score', which examines the current conditions of a patient that lead to or are affected by dyspnea; and 'impact scores' that measures social function and psychosocial disorders resulted from the respiratory illness. A total score is calculated, including
Respiratory Questionnaire. Lower spirometric parameters, 6min walk tests, and $\mathrm{SpO}_{2} \%$, were correlated with impaired HRQoL.

Conclusion Patients with COPD had reduced HRQoL. Frequent exacerbations, advanced airway obstruction, and dyspnea severity had negative impact on HRQoL. Egypt J Bronchol 2018 12:288-294 (C) 2018 Egyptian Journal of Bronchology

\section{Egyptian Journal of Bronchology 2018 12:288-294}

Keywords: chronic obstructive pulmonary disease, quality of life, St George', s respiratory questionnaire

${ }^{a}$ Chest Diseases Department, Faculty of Medicine for Girls, Al-Azhar

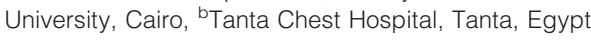

Correspondence to Eman S.M. Sobh, MD, Chest Diseases Department, Al-Zahraa University Hospital, Al-Abbassia, Cairo 11517, Egypt. Tel: +201005824279; fax: +20222638359; e-mail: emansobh@azhar.edu.eg

Received 15 February 2018 Accepted 20 March 2018

all items. Low scores indicate a better HRQoL [10]. The current management lines for COPD did not include assessment of HRQoL as a routine assessment. This study aimed to evaluate the QoL in COPD patients and its relationship to the severity of COPD.

\section{Patients and methods}

\section{Study design}

A cross-sectional observational multicentre study (AlZahraa University Hospital \& Tanta Chest Hospital) involved 200 stable COPD patients from January 2016 to January 2018.

All patients had symptoms of chronic airflow limitation and fulfilled GOLD [11] criteria for the diagnosis of COPD. All had postbronchodilator $\mathrm{FEV}_{1} / \mathrm{FVCl}$ ess than $70 \%$ of predicted value, and an increase in $\mathrm{FEV}_{1}$ less than $200 \mathrm{ml}$ or less than $12 \%$ of baseline value, $15-20 \mathrm{~min}$ after $400 \mathrm{mg}$ of inhaled salbutamol [12]. Demographic data, medical history, and examination data were recorded for each patient. The following tests were done:

This is an open access journal, and articles are distributed under the terms of the Creative Commons Attribution-NonCommercial-ShareAlike 4.0 License, which allows others to remix, tweak, and build upon the work non-commercially, as long as appropriate credit is given and the new creations are licensed under the identical terms. 
(1) Spirometry: was carried out using (Care Fusion Spirometry; Hoechberg, Germany) according to ERS/ATS guidelines. The best of three technically acceptable trials was selected [13]. The following indices were recorded $\mathrm{FEV}_{1}, \mathrm{FVC}$, and $\mathrm{FEV}_{1} /$ $\mathrm{FVC}, \mathrm{FEF}_{25-75 \%}, \mathrm{PEF}$. Airflow limitations were classified according to postbronchodilator $\mathrm{FEV}_{1} \%$ and to new GOLD, ABCD assessment tool [11].

(2) BODE index assessment: it includes BMI, $\mathrm{FEV}_{1} \%$, modified Medical Council Research Dyspnea scale (mMRC), and 6-minute walking distance (6MWD) [14-16].

(3) Assessment of HRQoL: using Arabic for Egypt version of SGRQ [10]. The questionnaire was selfadministered during an interview when the patients were sitting in a calm area, free from interruption, after obtaining consent and a full explanation of the purpose. We explained the questionnaire and stated that no ideal answers are expected, and requested simply to answer what they felt reflects their condition, without any directions from the researchers. Three SGRQ domains (symptom, activity, and impact scores) and the total score were calculated. The scores vary from 0 (no disability) to 100 (maximum disability indicating poorer QoL).

\section{Statistical analysis}

Data analyses were performed by using the mean, SD, and $\chi^{2}$ by using the (SPSS), version 20 (IBM Corp., Armonk, New York, USA). Qualitative data were expressed as number and percentage of the total, whereas parametric data were expressed as mean \pm SD. Multivariate linear regression was used for identification of different factors affecting SGRQ score. Significance level is considered at $P$-value less than 0.05 .

\section{Ethical statement}

The study was approved by the Institutional Ethical Review Board and Ethics Committee of the Faculty of Medicine for Girls, Al-Azhar University. All patients gave informed consent. Written permission to use St George's Respiratory Questionnaire in this study was obtained before starting the study through e-mail contact with the developers.

\section{Results}

We selected 200 COPD patients, men were predominant (72\%) and most of them (79\%) were more than 50 years old. Table 1 shows demographic and clinical characteristics of the studied COPD patients, patients had at least one exacerbation within the previous year. Comorbid illness were found in (56.5\%), hypertension was the most common comorbidity detected (34\%), followed by diabetes mellitus (18.5\%). The majority of patients (83\%) had mMRC dyspnea scale, grades 4 and 3, in addition; the majority of patients (93.5\%) ranging from moderate to very severe airway obstruction (GOLD grades 2, 3, and 4), mild obstruction (GOLD 1) recorded only in $6.5 \%$ of the patients. Concerning new GOLD, ABCD risk classification, most of them lie in grade $\mathrm{D}$, then grade $\mathrm{B}(53.5 \%, 45.0 \%)$, respectively. Table 2 indicates worsening of airflow limitations, more COPD symptoms with frequent exacerbations. We found reduced HRQoL across all SGRQ domains (symptom, activity, impact, and total scores). The activity score was the highest, indicating that the dyspnea is the most worrying symptom of COPD affecting the HRQoL (Table 3). Multivariate regression analysis was done to test different factors affecting COPD HRQoL to identify the key domains of HRQoL for patients with COPD (Table 4). The results of regression analysis show that the variables are linearly dependent. The major factors that have significant effect on the $\mathrm{QoL}$ in patients with COPD $(P<0.05)$ are $\mathrm{FEV}_{1} \%$, New GOLD, cardiac diseases, 6MWD, mMRC dyspnea scale, and

Table 1 Demographic and clinical data of the studied chronic obstructive pulmonary disease patients

\begin{tabular}{lc}
\hline Variables & Mean \pm SD/n $(\%)$ \\
\hline Age (years) & $58.30 \pm 9.12$ \\
$<50$ & $41(20.5)$ \\
$50-70$ & $147(73.5)$ \\
$>70$ & $12(6)$ \\
Sex & \\
Male & $144(72.0)$ \\
BMI (minimum-maximum) $\left(\mathrm{kg} / \mathrm{m}^{2}\right)$ & $24.33 \pm 2.79$ \\
& $(18.29-36.89)$ \\
Smoking habits & \\
Nonsmoker & $69(34.5)$ \\
Current smoker & $73(36.5)$ \\
Ex-smoker & $58(29.0)$ \\
Smoking pack/year & $37.29 \pm 25.18$ \\
COPD: duration/year & $11.02 \pm 7.46$ \\
Frequency of exacerbation & $3.53 \pm 1.98$ \\
(minimum-maximum) (year) & $(1.0-10.0)$ \\
Comorbidity & $113(56.5)$ \\
Type of comorbidity & \\
HTN & $68(34)$ \\
DM & $37(18.5)$ \\
IHD & $21(10.5)$ \\
Liver diseases & $20(10)$ \\
GERD & $15(7.5)$ \\
Renal diseases & $7(3.5)$ \\
CVA & $1(0.5)$ \\
\hline COPD chronicobstrctie & \\
\hline &
\end{tabular}

COPD, chronic obstructive pulmonary disease; CVA, cerebrovascular attack; DM, diabetes mellitus; GERD, Gastero-esophageal reflux; HTN, hypertension; IHD, ischemic heart diseases. 
exacerbations per year respectively. This model of regression can achieve accurate results by about $80 \%$ (adjusted $\left.R^{2}=0.806\right)$. It is statistically significant and accepted $(F=37.176)$.

In the current study, age, frequency of exacerbations per year, and comorbidity had a significant positive correlation with SGRQ total score and scores of all domains. Among the comorbidities hypertension had a

Table 2 Spirometric indices, BODE index and its parameters and St George's Respiratory Questionnaire score for the studied population $(n=200)$

\begin{tabular}{lc}
\hline Variables & Mean \pm SD $/ n(\%)$ \\
\hline FEV $_{1} \%$ & $50.76 \pm 19.80$ \\
$\mathrm{FVC} \%$ & $71.53 \pm 24.17$ \\
$\mathrm{FEV}_{1} / \mathrm{FVC}(\%)$ & $58.82 \pm 10.82$ \\
$\mathrm{FEF}_{25-75 \%}$ & $27.28 \pm 18.99$ \\
GOLD stage & \\
GOLD 1 mild & $13(6.5)$ \\
GOLD 2 moderate & $84(42.0)$ \\
GOLD 3 severe & $74(37.0)$ \\
GOLD 4 very severe & $29(14.5)$ \\
New GOLD & \\
Grade A & $0(0.0)$ \\
Grade B & $90(45.0)$ \\
Grade C & $3(1.5)$ \\
Grade D & $107(53.5)$ \\
BODE index & $6.14 \pm 2.28$ \\
6MWD & $158.57 \pm 80.16$ \\
mMRC dyspnea scale & $3.26 \pm 0.74$ \\
Grade 1 & $1(0.5)$ \\
Grade 2 & $33(16.5)$ \\
Grade 3 & $80(40.0)$ \\
Grade 4 & $86(43.0)$ \\
\hline BODE, body mass index,
\end{tabular}

BODE, body mass index, obstruction (airway), dyspnea, exercise; mMRC, modified Medical Council Research Dyspnea scale; 6MWD, 6 minute walk distance. significant positive correlation with the activity and impact scores ( $r=0.208$ and 0.228 , respectively), also, ischemic heart disease had a significant positive correlation with activity, impact, and total scores $(r=0.302,0.329$, and 0.325 , respectively). mMRC dyspnea scale, BODE index, and Gold stages had a significant positive correlation with SGRQ scores. However, 6-min walk tests, $\mathrm{SpO}_{2} \%$, and spirometric indices had a significant negative correlation with all SGRQ scores (Figs 1-3).

\section{Discussion}

In the current study; the mean age of Egyptian COPD patients was $(58.30 \pm 9.12)$, most of them $(79 \%)$ were more than 50 years old with majority as men (72\%); every patient had one or more exacerbations in the previous year. COPD is a male-dominant disease with a higher incidence in fifth and sixth decades of life $[17,18]$. This may be attributed to the difference in tobacco smoking/consumption in both sexes [19].

The current study demonstrates that COPD patient had significantly impaired HRQoL based on high SGRQ scores across (symptom, activity, impact, and total scores). Among all aspects affecting COPD, the

Table 3 St George's Respiratory Questionnaire scores in the studied group

\begin{tabular}{lc}
\hline Variables & Mean \pm SD/n (\%) \\
\hline SGRQ symptoms score & $65.42 \pm 17.42$ \\
SGRQ activity score & $68.85 \pm 21.38$ \\
SGRQ impact score & $56.47 \pm 19.97$ \\
SGRQ total score & $61.77 \pm 18.63$ \\
\hline
\end{tabular}

SGRO, St George's Respiratory Questionnaire.

Table 4 Multivariate linear regression for factors affecting St George's Respiratory Questionnaire

\begin{tabular}{|c|c|c|c|c|c|}
\hline & $B$ & SE & $\beta$ & $t$ & $P$ \\
\hline $\mathrm{FEV}_{1}$ & 0.155 & 0.061 & 0.164 & $2.526^{*}$ & $0.013^{*}$ \\
\hline New GOLD & 4.361 & 1.768 & 0.239 & $2.467^{*}$ & $0.015^{\star}$ \\
\hline IHD & -7.757 & 3.277 & -0.107 & $2.367^{\star}$ & $0.020^{*}$ \\
\hline 6MWD & -0.039 & 0.018 & -0.187 & $2.158^{*}$ & $0.034^{*}$ \\
\hline mMRC dyspnea scale & 4.809 & 2.218 & 0.193 & $2.168^{*}$ & $0.033^{*}$ \\
\hline Exacerbations/year & 0.972 & 0.468 & 0.124 & $2.076^{*}$ & $0.041^{*}$ \\
\hline Renal diseases & 4.107 & 2.272 & 0.092 & 1.808 & 0.074 \\
\hline Age & -0.137 & 0.116 & -0.062 & 1.183 & 0.240 \\
\hline $\mathrm{FEF}_{25-75 \%}$ & -0.294 & 0.176 & -0.315 & 1.672 & 0.098 \\
\hline FVC\% & 0.075 & 0.076 & 0.103 & 0.985 & 0.327 \\
\hline FVC/I & 1.505 & 1.094 & 0.085 & 1.376 & 0.172 \\
\hline $\mathrm{FEV}_{1} / \mathrm{FVC}(\%)$ & 0.040 & 0.100 & 0.026 & 0.405 & 0.687 \\
\hline BODE index & 1.375 & 1.267 & 0.169 & 1.086 & 0.280 \\
\hline GOLD stage & -1.481 & 3.278 & -0.066 & 0.452 & 0.652 \\
\hline Comorbidity & -10.905 & 10.080 & -0.059 & 1.082 & 0.282 \\
\hline \multicolumn{6}{|c|}{$R^{2}=0.850$, adjusted $R^{2}=0.816, \mathrm{SE}=7.48, F=24.905^{\star}, P<0.001^{*}$} \\
\hline
\end{tabular}

$B$, unstandardized coefficients; IHD, ischemic heart diseases; mMRC, modified Medical Council Research Dyspnea scale; $R$, coefficient of regression; $t$, $t$-test of significance. ${ }^{*} P \leq 0.05$, statistically significant. 


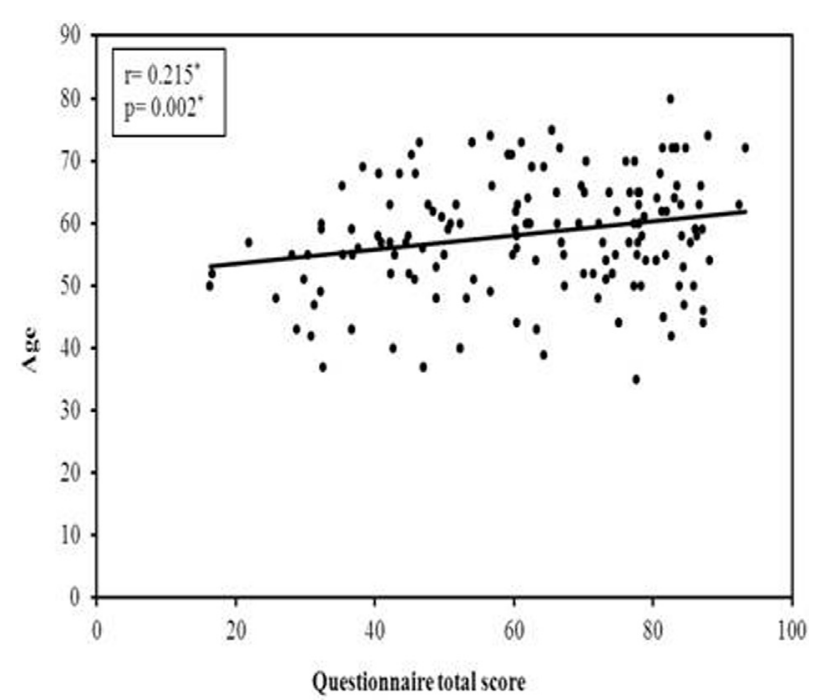

Correlation between age and St George's Respiratory Questionnaire.

Figure 2

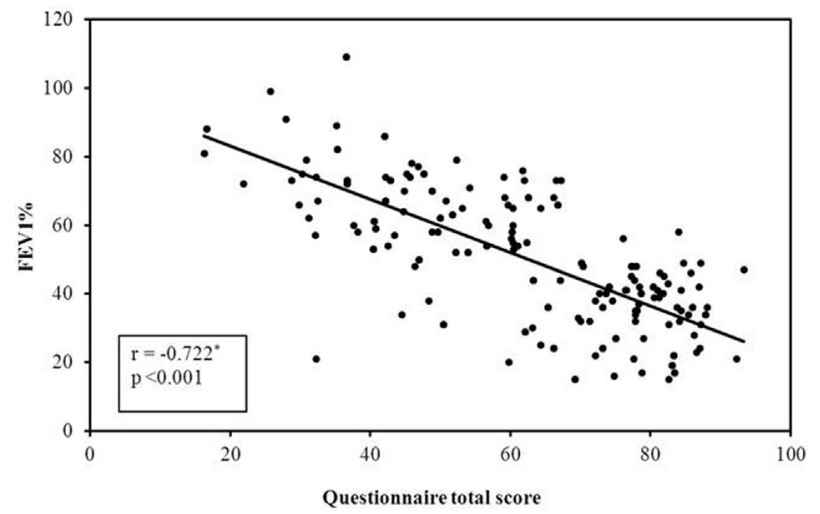

Correlation between FEV $1 \%$ and St George's Respiratory Questionnaire.

activity score was the highest, indicating that the dyspnea is the most distressing COPD symptom affecting HRQoL. The same results were reported in previous studies $[5,6,20]$. The effects of age on HRQoL have been researched in numerous clinical studies, and their results are controversial. In the current study, the HRQoL in COPD patients was adversely affected by age, there was a statistically significant positive correlation between age and SGRQ score with a strong linear relationship across all domains (Fig. 1), but the impact score is the highest $(P<0.002)$ indicating more worsening of social function and psychosocial disturbances with aging, this could be clarified by the fact that aging is usually linked with impaired activity, depressive symptoms, and anxiety. Similar results have been reported by many authors [20-23]. Conversely, others [24,25] found a nonsignificant correlation between age and HRQoL. However; Moy et al.
Figure 3

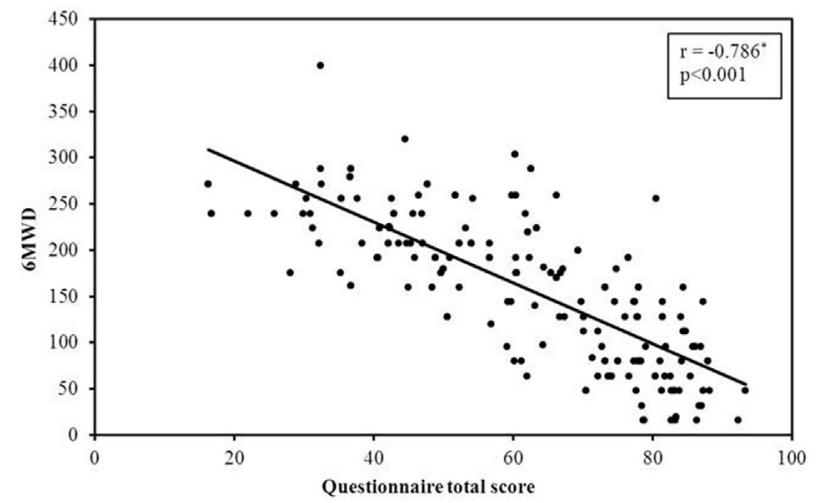

Correlation between 6 minute walk distance and St George's Respiratory Questionnaire.

[26], reported that HRQoL was more impaired in younger patients.

Concerning BMI, the current study demonstrated no correlations between BMI and HRQoL. Various studies $[27,28]$ showed that the correlation between the BMI and total SGRQ scores was weak. Moy et al. [26], have shown that the overweight patients have worse HRQoL. Sundh et al. [29], concluded that comorbidity and BMI are associated with impaired HRQoL in COPD patients. Katsura et al. [30], added that the patients with low BMI had poor HRQoL and suggested that the introduction of nutritional intervention might be beneficial to improve the QoL and dyspnea in those patients.

In terms of smoking habit, the majority of studied patients (65.5\%) are current and ex-smokers, no correlation is there between smoking and HRQoL by SGRQ score. The possible explanation may be that if once the impairment occurs, further exposure to smoking does not affect the overall HRQoL. Our results coincide with Katsura and colleagues [30-32]. They reported no significant adverse effect of smoking on SGRQ. However, Zamzam et al. [33], have shown that there was a statistically significant positive correlation between smoking index and both symptoms score and impact score. Whereas, the correlations between both total score and activity score and smoking pack/year were nonsignificant. Obaseki et al. [25], found that the heavy smokers had worse HRQoL symptom scores compared with nonsmokers. Also, Ahmed et al. [34] and Shavro et al. [35], showed a significant inverse correlation between smoking pack/year and HRQoL scores. On the other, a study carried out by Wijnhoven et al. [36], reported better HRQoL in current smokers. 
They explained that patients who are still smoking might be those with a less advanced stage of the disease.

In this study, COPD patients experienced at least one exacerbation within the previous year. The frequency of exacerbations illustrates strong linear relationship across all SGRQ domains $(P<0.001)$ suggesting that worse $\mathrm{HRQ}$ L is related to COPD exacerbations (Tables 1-4). Ekici et al. [37], reported that poor HRQoL was related to severity of COPD, dyspnea grade, and exacerbation frequency. Seemungal et al. [38], reported worse impact scores in patients with frequent past exacerbations. In addition, this study noted that $56.5 \%$ of the patients with COPD had comorbidities. Hypertension, diabetes mellitus, and ischemic heart diseases (IHD), are the most recorded comorbidities. All domains of SGRQ scores are adversely affected by comorbidities $(P<0.001)$. IHD and hypertension were statistically correlated with activity and impact score, indicating that impaired DAs, breathlessness, fatigue, psychosocial disturbances, and anxiety are more common in COPD with cardiovascular disorders. IHD is one of the most significant factors affecting the QoL of patients with COPD $(P<0.02)$. Huber et al. [39], concluded that there was significant negative association between comorbidities and HRQLL in COPD.

Concerning lung function assessment most of our studied patients have advanced airflow limitations, more COPD symptoms with frequent exacerbations. The SGRQ score worsens considerably with increasing disease severity. The worst scores were detected among advanced stages of COPD (Table 2).

Miyazaki et al. [40] and Burgel et al. [24], documented a significant correlation between COPD severity and SGRQ. As the degree of severity increases, the more impaired is the SGRQ. Zamzam et al. [33], concluded that there was a statistically significant negative correlation between $\mathrm{FEV}_{1}, \mathrm{FEV}_{1} / \mathrm{FVC}$, PEFR, $\mathrm{FEF}_{25-75 \%}$, and SGRQ score. In addition, Jones et al. [41], reported that HRQoL impairment varied extensively within each GOLD stage of severity, and marked HRQoL impairment takes place even in the early stages of COPD with little variability between patients in GOLD stage I and II. However, Ong et al. [42], concluded that COPD stage according to GOLD had a mild correlation with SGRQ.

Previous studies documented impaired physical activity in COPD patients [43]. In this study, patients with
COPD had impaired physical activity determined by advanced grades of dyspnea, limited 6MWD, and high BODE index score (Table 2) affecting their HRQoL. The majority of the patients (83\%) had mMRC dyspnea grades 4 and 3, indicating high subjective dyspnea with a higher degree of disability, it also predicts future mortality risk. Also, we found a significant positive correlation between SGRQ and both BODE index and $\mathrm{mMRC}$ dyspnea with a strong linear relationship across all domains $(P<0.001)$. However; there was a significant negative correlation between the 6MWD and all SGRQ domains. The 6MWD and $\mathrm{mMRC}$ are good predictors of HRQoL in patients with COPD $(P<0.05)$ (Table 4). The previous data indicate that BODE index and its parameters have excellent discriminative capabilities, to detect the deterioration of HRQoL earlier and predicts future mortality risk to take appropriate and effective actions to relieve patients' symptoms, improve patients' exercise tolerance, and slow down disease progression. Numerous studies reported the same results, Nonato et al. [44] and Sarkar et al. [27], concluded that BODE index showed very strong correlation with the total SGRQ score, activity and impact domain of SGRQ score, but showed moderate correlation with the symptom domain. Other studies [45-47] reported that the 6-min walk tests correlated with all domains and with the total score of the SGRQ. Many researchers [27,28,45] concluded that mMRC scale for dyspnea showed a positive correlation with the QoL in variable degrees.

Using multiple regression analysis, it was demonstrated that FEV1, new GOLD stage, IHD, mMRC, exacerbations per year, and 6MWD were the best predictor of impaired HRQoL assessed by the SGRQ score. Although, age, other spirometry parameters, BODE index, and GOLD stage have significant correlations with the SGRQ. In the multiple regression analysis; all variables were ruled out as predictive variables.

This study has some strengths including large sample size, different modalities to examine functional status (spirometry, 6MWD, and BODE index). But we still have some limitations; the most important is the small number of female participant, reflecting the fact that the number of women with COPD seen in our clinical practice is low. However, this has been seen in previous studies. Also, the number of participants in GOLD stage 1 are significantly low. So; nearly our results measured HRQoL in moderate to very severe cases. This is because most patients with COPD in our community seek medical assistance only when they have significant symptoms and advanced airway obstruction. 


\section{Conclusion}

This study suggests that the SGRQ is of great value for evaluating the impact of HRQoL on COPD. SGRQ appears to be more useful than the approaches that employ single parameters, such as $\mathrm{FEV}_{1}$. So measurement of HRQoL should be considered in addition to spirometry for evaluation of COPD patients.

\section{Financial support and sponsorship \\ Nil.}

\section{Conflicts of interest}

There are no conflicts of interest.

\section{References}

1 Paap MC, Bode C, Lenferink LI, Terwee CB, van der Palen J. Identifying key domains of health-related quality of life for patients with chronic obstructive pulmonary disease: interviews with healthcare professionals. Qual Life Res 2015; 24:1351-1367.

2 Metwally MM. Validity and reliability of the first Arabic version of St George's respiratory questionnaire after adaptation to a completely different language and culture. Thematic poster abstract at: European Respiratory Society Annual Congress 2004 September 4-8 Glasgow, Scotland, UK. Available at: http://www.ers-education.org/events/ international-congress/glasgow-2004.aspx?idParent=16351. [Accessed 13 March 2018]

3 Habraken JM, Pols J, Bindels PJ, Willems DL. The silence of patients with end-stage COPD: a qualitative study. Br J Gen Pract 2008; 58:844-849.

4 Yohannes AM. Palliative care provision for patients with chronic obstructive pulmonary disease. Health Qual Life Outcomes 2007; 5:17.

5 Avsar G, Kasikci M. Living with chronic obstructive pulmonary disease: a qualitative study. Aust J Adv Nurs 2010; 28:46.

6 Kessler R, Partridge MR, Miravitlles M, Cazzola M, Vogelmeier C, Leynaud D, Ostinelli J. Symptom variability in patients with severe COPD: a panEuropean cross-sectional study. Eur Respir J 2011; 37:264-272.

7 Negi H, Sarkar M, Raval AD, Pandey K, Das P. Health-related quality of life in patients with chronic obstructive pulmonary disease in North India. $J$ Postgrad Med 2014; 60:7.

8 Pereira ED, Pinto R, Alcantara M, Medeiros M, Mota RM. Influence of respiratory function parameters on the quality of life of COPD patients. $J$ Bras Pneumol 2009; 35:730-736.

9 Jones PW, Quirk FH, Baveystock CM, Littlejohns P. A self-complete measure of health status for chronic airflow limitation. Am Rev Respir Dis 1992; 145:1321-1327.

10 Jones PW. George's respiratory questionnaire: MCID. COPD 2005; 2:75-79.

11 Global Strategy for the Diagnosis, Management and Prevention of COPD Global Initiative for Chronic Obstructive Lung Disease (GOLD) 2017. Available at: http://goldcopd.org/. [Accessed 30 December 2017]

12 Pavord ID, Jones PW, Burgel PR, Rabe KF. Exacerbations of COPD. International journal of chronic obstructive pulmonary disease. 2016; 11:21.

13 Miller MR, Hankinson JA, Brusasco V, Burgos F, Casaburi R, Coates A, et al. Standardisation of spirometry. Eur Respir J 2005; 26:319-338.

14 Celli BR, Cote CG, Marin JM, Casanova C, Montes de Oca M, Mendez RA, et al. The body-mass index, airflow obstruction, dyspnea, and exercise capacity index in chronic obstructive pulmonary disease. $N$ Engl J Med 2004; 350:1005-1012.

15 Enright PL. The six-minute walk test. Respir Care 2003; 48:783-785.

16 Launois C, Barbe C, Bertin E, Nardi J, Perotin JM, Dury S, Lebargy F, Deslee G. The modified Medical Research Council scale for the assessment of dyspnea in daily living in obesity: a pilot study. BMC Pulm Med 2012; 12:61.?

17 Hurd S. The impact of COPD on lung health worldwide: epidemiology and incidence. Chest 2000; 117:1S-4S.

18 Sullivan SD, Ramsey SD, Lee TA. The economic burden of COPD. Chest 2000; 117:5S-9S.
19 Aryal S, Diaz-Guzman E, Mannino DM. Influence of sex on chronic obstructive pulmonary disease risk and treatment outcomes. Int $J$ Chron Obstruct Pulmon Dis 2014; 9:1145.

20 Sharma K, Joshi S. Quality of life of patients with chronic obstructive pulmonary disease in Chitwan, Nepal: a pilot study report. Int J Med Sci Public Health 2015; 4:1235-1241.

21 Dignani L, Toccaceli A, Lucertini C, Petrucci C, Lancia L. Sleep and quality of life in people with COPD: a descriptive-correlational study. Clin Nurs Res 2016; 25:432-447.

22 Miravitlles M, Molina J, Naberan K, Cots JM, Ros F, Llor C. Factors determining the quality of life of patients with COPD in primary care. Ther Adv Respir Dis. 2007; 1 (2):85-92.

23 Hesselink AE, van Der Windt DA, Penninx BW, Wijnhoven HA, Twisk JW, Bouter LM, et al. What predicts change in pulmonary function and quality of life in asthma or COPD?. J Asthma 2006; 43:513-519.

24 Burgel PR, Escamilla R, Perez T, Carré P, Caillaud D, Chanez P, et al. Impact of comorbidities on COPD-specific health-related quality of life. Respir Med 2013; 107:233-241.

25 Obaseki DO, Erhabor GE, Awopeju OF, Obaseki JE, Adewole OO. Determinants of health related quality of life in a sample of patients with chronic obstructive pulmonary disease in Nigeria using the St. George's respiratory questionnaire. Afr Health Sci 2013, 13:694-702

26 Moy ML, Reilly JJ, Ries AL, Mosenifar Z, Kaplan RM, Lew R, et al. Multivariate models of determinants of health-related quality of life in severe chronic obstructive pulmonary disease. J Rehabil Res Dev 2009; 46:643.

27 Sarkar SK, Basuthakur S, Das SK, Das A, Das S, Choudhury S, et al. Evaluation of correlation of BODE index with health-related quality of life among patients with stable COPD attending a tertiary care hospital. Lung India 2015; 32:24.

28 Lin YX, Xu WN, Liang LR, Pang BS, Nie XH, Zhang J, et al. The crosssectional and longitudinal association of the BODE index with quality of life in patients with chronic obstructive pulmonary disease. Chin Med $\mathrm{J}$ (Engl) 2009; 122:2939-2944.

29 Sundh J, Ställberg B, Lisspers K, Montgomery SM, Janson C. Comorbidity, body mass index and quality of life in COPD using the clinical COPD questionnaire. COPD 2011;8173-181

30 Katsura H, Yamada K, Kida K. Both generic and disease specific healthrelated quality of life are deteriorated in patients with underweight COPD. Respir Med 2005; 99:624-630.

$31 \mathrm{Kwon} \mathrm{HY,} \mathrm{Kim} \mathrm{E.} \mathrm{Factors} \mathrm{contributing} \mathrm{to} \mathrm{quality} \mathrm{of} \mathrm{life} \mathrm{in} \mathrm{COPD} \mathrm{patients} \mathrm{in}$ South Korea. Int J Chron Obstruct Pulmon Dis 2016; 11:103.

32 Garrido PC, de Miguel Díez J, Gutiérrez JR, Centeno AM, Vázquez EG, de Miguel ÁG, et al. Negative impact of chronic obstructive pulmonary disease on the health-related quality of life of patients. Results of the EPIDEPOC study. Health Qual Life Outcomes 2006; 4:31.

33 Zamzam MA, Azab NY, EI Wahsh RA, Ragab AZ, Allam EM. Quality of life in COPD patients. Egypt $J$ Chest Dis Tuberc 2012; 61:281-289.

34 Ahmed MS, Neyaz A, Aslami AN. Health-related quality of life of chronic obstructive pulmonary disease patients: Results from a community based cross-sectional study in Aligarh, Uttar Pradesh, India. Lung India 2016 33:148.

35 Shavro SA, Ezhilarasu P, Augustine J, Bechtel JJ, Christopher DJ. Correlation of health-related quality of life with other disease severity indices in Indian chronic obstructive pulmonary disease patients. Int $J$ Chron Obstruct Pulmon Dis 2012; 7:291.

36 Wijnhoven HA, Kriegsman DM, Hesselink AE, Penninx BW, de Haan M Determinants of different dimensions of disease severity in asthma and COPD: pulmonary function and health-related quality of life. Chest 2001 119:1034-1042.

37 Ekici A, Bulcun E, Karakoc T, Senturk E, Ekici M. Factors associated with quality of life in subjects with stable COPD. Respir Care 2015; 60 : 1585-1591.

38 Seemungal TA, Donaldson GC, Paul EA, Bestall JC, Jeffries DJ, Wedzicha JA. Effect of exacerbation on quality of life in patients with chronic obstructive pulmonary disease. Am J Respir Crit Care Med 1998; 157 1418-1422.

39 Huber MB, Wacker ME, Vogelmeier CF, Leidl R. Comorbid influences on generic health-related quality of life in COPD: a systematic review. PLoS One 2015; 10:e0132670.

40 Miyazaki M, Nakamura H, Chubachi S, Sasaki M, Haraguchi M, Yoshida S, et al. Analysis of comorbid factors that increase the COPD assessment test scores. Respir Res 2014; 15:13. 
41 Jones PW, Brusselle G, Dal Negro RW, Ferrer M, Kardos P, Levy M, et al. Health-related quality of life in patients by COPD severity within primary care in Europe. Respir Med 2011; 105:57-66.

42 Ong KC, Lu SJ, Soh CS. Does the multidimensional grading system (BODE) correspond to differences in health status of patients with COPD?. Int J Chron Obstruct Pulmon Dis 2006; 1:91.

43 Galal-Eldin MM, Ahmad SE, Hafez RM, Sobh E, Alrayes HM. Telomere length in chronic obstructive pulmonary disease. Egypt J Bronchol 2015; 9:20-26.

44 Nonato NL, Díaz O, Nascimento OA, Dreyse J, Jardim JR, Lisboa C. Behavior of quality of life (SGRQ) in COPD patients according to BODE scores. Arch Bronconeumol 2015; 51:315-321.
45 Konwar G, Sarma J. A study of health related quality of life in COPD patients in relation to severity of disease. Assam J Int Med 2015; 5:22-25.

46 Santos KD, Karloh M, Araujo CL, D'Aquino AB, Mayer AF. Relationship between the functional status constructs and quality of life in COPD. Fisioter Mov 2014; 27:361-369.

47 Busby AK. Sex Differences in Inflammation, Psychological Functioning, and Disease Outcomes Among COPD Patients Participating in Pulmonary Exercise Rehabilitation. Electronic Thesis or Dissertation. Ohio State University, 2010. OhioLINK Electronic Theses and Dissertations Center. [Last accessed 15 February 2018]. 